\title{
Use of AlloDerm Graft for Repairing Nasoseptal Perforation
}

\author{
Alireza Mohebbi ${ }^{1,2}$, Hosna Zobairy ${ }^{1,2}$, Hesam Jahandideh ${ }^{1,3}$ and Ayda Sanaei ${ }^{1,2,{ }^{*}}$ \\ ${ }^{1}$ ENT and Head and Neck Research Center, The Five Senses Institute, Iran University of Medical Sciences (IUMS), Tehran, Iran \\ ${ }^{2}$ ENT and Head and Neck Research Center and Department, Five Senses Health Research Institute, Hazrat Rasoul Akram Hospital, Iran University of Medical Sciences (IUMS), \\ Tehran, Iran \\ ${ }^{3}$ Department of Otolaryngology and Head and Neck Surgery, Firoozgar Hospital, Iran University of Medical Sciences (IUMS), Tehran, Iran \\ "Corresponding author: ENT and Head and Neck Research Center and Department, Hazrat Rasoul Akram Hospital, Iran University of Medical Sciences (IUMS), Satarkhan St., \\ Postal code: 1445613131, Tehran, Iran. Tel: +98-2166515001, Email: aidasanayi@gmail.com
}

Received 2019 March 09; Revised 2020 May 12; Accepted 2020 May 15.

Keywords: AlloDerm Graft, Repair, Nasoseptal Perforation, Rhinoplasty Surgery

\section{Dear Editor,}

Nasal septum perforation (NSP) is a potential complication of septorhinoplasty that should be considered a risk for the surgical procedure. However, NSP may have other causes such as trauma, infection, degeneration, overuse of vasoconstrictors, abuse of cocaine, and chemotherapy agents. Nowadays, NSP is increasing due to increases in septorhinoplasty $(1,2)$. Many surgical procedures have been proposed to repair the defect either by endonasal approaches using mucoperichondrial flaps or combined flaps such as interpositional grafts using septal cartilages, middle turbinate flaps, auricular or costal cartilage, and temporal fascia or using other non-autologous tissues and synthetic materials (3-5).

In recent years, acellular dermal allograft has been used as a graft material in NSP, eliminating the need for autogenous materials. The acellular dermal allograft can be used with other flaps such as inferior turbinate flaps, with different success rates, and is processed by human donor skin from approved tissue banks. The epidermis is removed, and the rest of the dermal layer is washed with detergent and antiviral solutions to remove cellular components (6-8). This study aimed to describe the use of AlloDerm for the repair of NSP without any other flap, its success rate, and the possibility of growth over AlloDerm.

In this study, seven patients, including two females and five males with a median age of 48 years (range 32 to 65 years) underwent the AlloDerm graft procedure in the ENT Department of Rasoul Akram during 2013 - 2015. The research followed the tenets of the Declaration of Helsinki. Written informed consent was obtained, and the patients were free to leave the study at any time. All patients had symptomatic anterior septal perforation ranging from 0.5 to $2.5 \mathrm{~cm}$. None of the patients had ever been diagnosed with substance abuse and had no previous medical conditions. The main etiology for NSP was a previous surgery of the nasal septum, and only two of them had a history of digital trauma. The major symptom was a feeling of nasal obstruction. The procedure was done in open septorhinoplasty incision in two patients who had a nasal deformity and required revision rhinoplasty. Other patients underwent close septoplasty in a conventional pattern, and the mucoperichondrial flap was elevated with hemitransfixation incision. The edges of the perforation were debrided, and the mucoperichondrial flaps were raised around the margin of the perforation. A zero-degree endoscope was used for superior and posterior borders to fresh n perforation more than 1.5 centimeters (Figure 1). The allograft was rehydrated by soaking in saline for $10 \mathrm{~min}$ and then trimmed to the appropriate size. Then, it was positioned beneath the edge of perforation and secured in place with Vicryl suture an internal splint. At least $1 \mathrm{~cm}$ of AlloDerm was overlapped with mucosa.

The internal splint was removed after about four weeks with a septum examination by an endoscope. It is worth mentioning that two patients with a previous history of rhinoplasty, who complained of tip ptosis in one and saddle dorsum in the other, underwent open rhinoplasty approach to correct this problem. One of them (case F1) had a history of open septorhinoplasty 15 years ago, and NSP had been repaired with a titanium mesh six years ago. No mucoperichondrium was observed over the titanium mesh, and it was full of crusting. The chief complaint of the patient was malodor breathing. The mesh was removed and 


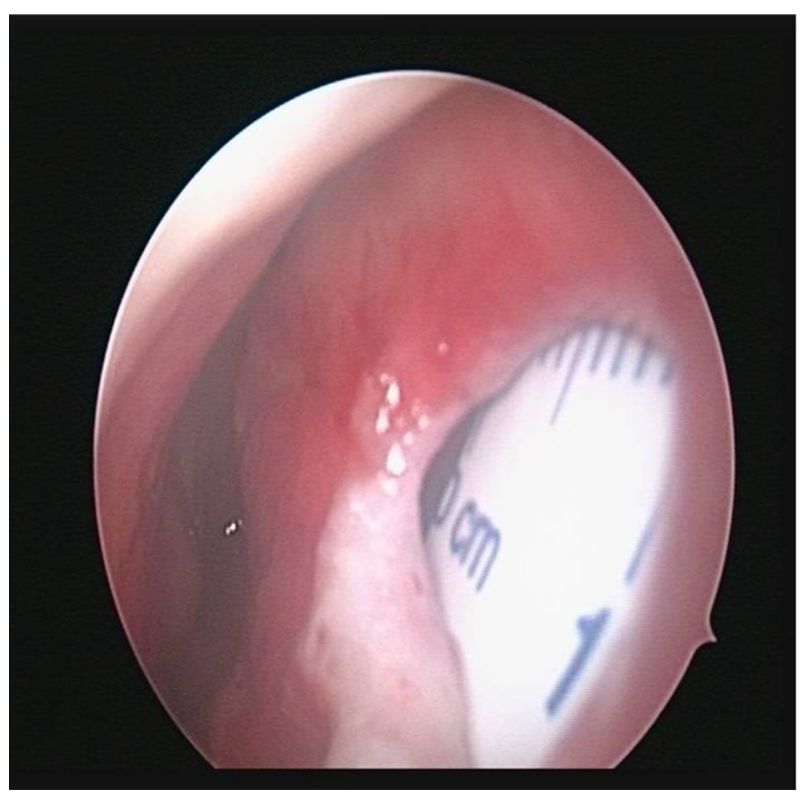

Figure 1. Measurement of perforation size in a patient with a history of rhinoplasty surgery

replaced with AlloDerm. Additionally, interdomain suture was used to retrieve tip ptosis. In the other patient (case F2) who had a history of open septorhinoplasty five years ago with a chief complaint of saddle nose deformity, AlloDerm was used for dorsal augmentation and nasoseptal deformity correction.

Totally, seven patients underwent the NSP repairing surgery using AlloDerm grafts and only two patients with small perforation $(<1 \mathrm{~cm})$ were cured completely. In these two patients, only the mucosa grew around the perforation edges $(2 \mathrm{~mm})$. In two patients who underwent revision rhinoplasty, the overall outcome was satisfying after the improvement of ptosis and dorsum although no improvement in NSP was achieved (Table 1).

Despite great advances in the field of septorhinoplasty, the treatment of NSP is still a challenging issue. Various methods have been recommended for surgery, including advancement flaps, local flaps, and external materials such as titanium mesh or AlloDerm, with different degrees of success $(3-5,9)$. The success of these methods depends on several factors including the perforation size, the experience of the surgeon, primary cause, postoperative care, and underlying disease $(1,10)$. Acellular dermal allograft has been used since 1992 as a dermal replacement graft for patients with burning. It has been used as an interpositional graft after experimental evidence that it acts as an excellent scaffold for reepithelialization of cutaneous and mucosal surfaces $(6,7)$. Acellular dermal allograft has several advantages, including the elimination of donor site morbidity, availability in quantities sufficient for all perforation sizes, and simplicity. Kridel et al. (6), in 1998 for the first time, described the use of AlloDerm as an interpositional graft in NSP in 12 patients. Eleven out of 12 patients had successful outcomes with complete closure of perforation. Friedman et al. in 2003 described a closed endoscopic repair technique to develop an inferior turbinate flap with AlloDerm as an interpositional graft (11). The successful closure rate was $76.5 \%$ with perforations ranging from $1 \mathrm{~cm}$ to $2.5 \mathrm{~cm}$ using a unilateral intranasal mucosal flap in most of the patients. Studies on the use of AlloDerm without advancement flap or local flap have been rarely considered (2). In our study, the effectiveness of AlloDerm for the reconstruction of septum depends on the perforation size. In this way, the perforations that were less than $1 \mathrm{~cm}$ without a history of previous surgery were closed completely, while graft failure was observed in large perforations and damaged mucosa.

Previous studies used AlloDerm as supporting material for local or advancement flaps. However, we used AlloDerm as a scaffold flap for mucosal growth. We realized that it can be enough for small perforation, while for larger ones, it cannot be used, and other flaps should be simultaneously used for mucosal growth. However, it is essential to conduct future studies with larger sample sizes for obtaining information regarding all possibilities for more specific results and final decision.

\section{Footnotes}

Authors' Contribution: All authors participated in the draft, concept, and revision of the paper.

Conflict of Interests: We have no conflicts of interest to disclose.

Ethical Approval: The ethical approval code was IR.IUMS.rec.1393.9111369002.

Funding/Support: None. 


\begin{tabular}{lcccll}
\hline \multicolumn{2}{l}{ Table 1. The Outcome of the Study Alongside Etiologies } \\
\hline Code & Sex & Age & Etiology & Size & Outcome \\
\hline $\mathbf{1}$ & F & 52 & Septorhinoplasty & $2.3 \times 2.2$ & Graft failure \\
$\mathbf{2}$ & F & 32 & Septorhinoplasty & $1.8 \times 1.5$ & Graft failure \\
$\mathbf{3}$ & $\mathrm{M}$ & 33 & Septoplasty & $2.5 \times 2$ & Initial success, then 2-mm perforation at two months \\
$\mathbf{4}$ & $\mathrm{M}$ & 42 & Digital trauma & $0.5 \times 0.6$ & Success \\
$\mathbf{5}$ & $\mathrm{M}$ & 61 & Septoplasty & $1.2 \times 1.3$ & Initial success, then 2-mm perforation at two months \\
$\mathbf{6}$ & $\mathrm{M}$ & 65 & Septoplasty & $2.5 \times 2$ & Graft failure \\
7 & $\mathrm{M}$ & 55 & Digital trauma & $0.5 \times 0.3$ & Success \\
\hline
\end{tabular}

\section{References}

1. Teichgraeber JF, Riley WB, Parks DH. Nasal surgery complications. Plast Reconstr Surg. 1990;85(4):527-31. doi: 10.1097/00006534199004000-00006. [PubMed: 2315392].

2. Flint PW, Haughey BH, Niparko JK, Richardson MA, Lund VJ, Robbins $\mathrm{KT}$, et al. Cummings otolaryngology-head and neck surgery e-book: Head and neck surgery, 1-volume set. Elsevier Health Sciences; 2014.

3. Raol N, Olson K. A novel technique to repair moderate-sized nasoseptal perforations. Arch Otolaryngol Head Neck Surg. 2012;138(8):714-6. doi: 10.1001/archoto.2012.1204. [PubMed: 22801606].

4. Kridel RW, Foda H, Lunde KC. Septal perforation repair with acellular human dermal allograft. Arch Otolaryngol Head Neck Surg. 1998;124(1):73-8. doi: 10.1001/archotol.124.1.73. [PubMed: 9440784].

5. Ayshford CA, Shykhon M, Uppal HS, Wake M. Endoscopic repair of nasal septal perforation with acellular human dermal allograft and an inferior turbinate flap. Clin Otolaryngol Allied Sci. 2003;28(1):29-33. doi: 10.1046/j.1365-2273.2003.00654.x. [PubMed: 12580877].

6. Nunez-Fernandez D, Vokurka J, Chrobok V. Bone and temporal fascia graft for the closure of septal perforation. J Laryngol Otol.
1998;112(12):1167-71. doi: 10.1017/s0022215100142744. [PubMed: 10209613].

7. Ozkul HM, Balikci HH, Karakas M, Bayram O, Bayram AA, Kara N. Repair of symptomatic nasoseptal perforations using mucosal regeneration technique with interpositional grafts. J Craniofac Surg. 2014;25(1):98102. doi: 10.1097/SCS.ob013e3182a2eac6. [PubMed: 24240769].

8. Kridel RW. Considerations in the etiology, treatment, and repair of septal perforations. Facial Plast Surg Clin North Am. 2004;12(4):435-50. vi. doi: 10.1016/j.fsc.2004.04.014. [PubMed: 15337112].

9. Daneshi A, Mohammadi S, Javadi M, Hassannia F. Repair of large nasal septal perforation with titanium membrane: Report of 10 cases. Am J Otolaryngol. 2010;31(5):387-9. doi: 10.1016/j.amjoto.2009.04.009. [PubMed: 20015781].

10. Kridel RW, Appling WD, Wright WK. Septal perforation closure utilizing the external septorhinoplasty approach. Arch Otolaryngol Head Neck Surg. 1986;112(2):168-72. doi: 10.1001/archotol.1986.03780020048011. [PubMed: 3510639].

11. Friedman M, Ibrahim H, Ramakrishnan V. Inferior turbinate flap for repair of nasal septal perforation. Laryngoscope. 2003;113(8):1425-8. doi: 10.1097/00005537-200308000-00031. [PubMed: 12897571]. 